\title{
Effects of drying pattern on aflatoxin in stored paddy rice
}

\author{
S. Masood, Alim-un-Nisa *, S. Hina and I. Ahmad \\ PCSIR Labs Complex, Food \& Biotechnology Research Center, Ferozepur Road, Lahore, Pakistan
}

\section{Abstract}

Received: 11 December 2017

Revised: 17 January 2018

Accepted: 31 January 2018

DOI: http://dx.doi.org/10.3329/bjsir.v53i4.39188
This study was done to evaluate the impact of drying pattern on the accumulation of aflatoxin in paddy rice during storage. Two drying pattern includes, 1) single step drying to reduced the moisture content of paddy rice 11-12\% within 6 hours and stored for long time; and 2) two steps drying to reduce the moisture up to $18 \%$, in its first step and stored for short term (2 weeks) and in the second step, dried again to reduce the moisture content up to $11-12 \%$ and stored for longer time, with twenty five different paddy rice samples having moisture content ranging from $24-22 \%$ were evaluated for the accumulation of aflatoxins in paddy rice during storage. In addition, this study also evaluated the best drying method that can control the accumulation of aflatoxin during prolong storage. The study results revealed that one step drying is safer than that of two steps drying in accumulating aflatoxins in paddy rice during 210 days of storage. The maximum total aflatoxins (B1, B2, G1,G2) was recorded as $27 \mathrm{ppb}$ in paddy rice sample in two steps drying process, on the other hand, non-detectable level or $<10$ ppb level of aflatoxins was recorded in all the 25 paddy rice samples analyzed.

Keywords: Paddy rice; Aflatoxin accumulation; Moisture content and drying patterns

\section{Introduction}

Rice (Oryza sativa) is an important staple food and occupies second place in production area after wheat and maize worldwide. Pakistan is famous for rice production and is the third largest rice producing country after wheat and cotton area wise (Khan, 2010). Pakistan is still using the traditional paddy cultivation and harvesting method, hence, the quality and production yield greatly affected and more than 20 to $30 \%$ post-harvest losses have been reported (Khan and Salim, 2005). Drying is a critical step during rice post-harvest practices; inadequate drying and storage operations contribute to increased losses (Kumar and Kalita, 2017). When harvesting the paddy, the moisture content ranged between $24-26 \%$, and the respiration rate is high, this condition favors the microbes, insects and other pests to attach to the paddy. Therefore, drying within short time after harvest is recommended, and drying to obtain maximum $14 \%$ moisture content is safe for storage and milling. However, in case of difficulty, drying to obtain moisture content maximum $18 \%$ can be done for temporary storage ( 2 weeks) (Genkawa et al., 2008). On the other hand, bad drying practices may cause 1-5\% quality losses of paddy (Nguyen and Kunze, 1984). Therefore, to minimize the post-harvest losses, good drying practices are crucial that directly influence safe storage, transportation, distribution and processing quality. The recommended temperature for drying paddy is $43^{\circ} \mathrm{C}$ and mostly attained with shade drying (Siebenmorgen and Meullenet, 2004). Unlike like other developing countries, the farmers of Pakistan also use sun- or solar drying method due to its cost effectiveness. Although artificial or mechanical drying method speeds up drying process, reduces handling losses, maintains grain quality and gives better control during drying, but yet in common practice. Delayed drying may result in non-enzymatic browning (stack-burning), microbial growth and mycotoxin production (Riaz et al., 2017; Taechapairoj et al., 2007). 
Aflatoxins are secondary metabolites produced by some strains of mold including Aspergillus flavus and other species of Aspergillus fungi (Creppy, 2002). The four most common aflatoxins are B1, B2, G1, and G2. Contaminated grains and grain byproducts are the most common sources of aflatoxin (Bennett and Klich, 2003). Aflatoxins are metabolized in ruminants by the liver and are excreted in the bile. Aflatoxin B1 is the most potent mycotoxin and potent carcinogen (cancer causing agent) (de Ruyck et al., 2015; Fung and Clark, 2004; Nisa et al., 2014). The development of aflatoxins depends on the infestation and growth of the Aspergillus mold in grain and higher temperatures and humidity favor the growth. Harvested rice that remains in the field or rice that is stored without adequate drying can be subject to Aspergillus growth and aflatoxin production (Prietto et al., 2015; Nisa et al., 2014). Temperatures between $26-37^{\circ} \mathrm{C}$ and relative humidity of $85 \%$ (corresponding to 18 percent grain moisture) are optimum for growth of Aspergillus. On the other hand, the growth of Aspergillus is poor below $12^{\circ} \mathrm{C}$, but if the grain is moist enough, toxins can still be produced (Paterson and Lima, 2010; Mannaa et al., 2017). However, simply reducing the moisture content to as low as 12 percent, does not kill the fungus, nor reduce the levels of toxins that have already been produced. If moisture and temperature levels rise again above 12 percent, and elevated level, respectively, anytime during storage, then mold growth and toxin production will resume. It is important to note that conditions favoring the growth of Aspergillus also favor the growth of other fungi that can have harmful effects on humans if they are inhaled or ingested while working in grain handling facilities (Accinelli et al., 2014). Harvesting paddy rice containing 20\% moisture content and drying within 24 hours to reduce the moisture content no greater than $14 \%$ greatly inhibit the growth, and toxin production by Aspergillus. Maximum moisture content for corn storage should be 14 percent and moisture content below 12 percent is ideal for rice storage (Mohapatra et al., 2017; Bradford et al., 2017).

Aflatoxicosis can only be prevented by consuming toxin free diet and poor post harvest handling is the major cause of aflatoxin production in food grains. (Ashiq, 2015; Nisa et al., 2016). In general, hot and humid conditions are very favorable for the growth of toxigenic fungi and mycotoxin production in agricultural produce. (Neme and Mohammed, 2017; Medina et al., 2017). Thus, drying the food grains up to an optimum moisture level soon after harvest is of utmost importance in order to control aflatoxin production in agricultural commodities. The aim of present work is to evaluate the accumaltion of aflatoxin in paddy by comparing two different drying patterns includes, 1) single step drying to reduce the moisture content of paddy rice 11-12\% within 6 hours and stored for long time; and 2) two steps drying to reduce the moisture up to $18 \%$, in its first step and stored for two weeks and in the second step, dried again to reduce the moisture content up to $11-12 \%$ for prolong storage.

\section{Materials and methods}

Freshly harvested paddy samples were collected from different lots procured from Gujranwala district of Punjab province of Pakistan. Total fifty samples were collected from 25 lots i.e two samples from each lot and analyzed for the presence of aflatoxin. Five $(5 \mathrm{~kg})$ kilogram of each of the twenty five samples were dried up to moisture level $12-13 \%$ in a Mitchell cabinet tray dryers (Mitchell Dryers Ltd, Manchester, UK) within twenty four hours of harvesting and stored at temperature $35^{\circ} \mathrm{C}$ while other twenty five samples from same lot were sun dried and husked as per traditional practices. Huskers dried the sample in two steps: 1) at first samples were dried up to 11 to $12 \%$ moisture level for 3 days then stored at temperature $30^{\circ} \mathrm{C}$ and humidity $60 \%$ in a godown. 2) final drying was carried out to reduce the moisture level up to $13 \%$ after 2 weeks of first drying. After seven months of storage all samples were analyzed for alfatoxin content using VITCAM flouromer model 4EX (VITCAM, MA, USA) according to the manufacturer's instructions or as described by Mehan et al., 1985.

\section{Statistical Analysis}

All the samples were analyzed in triplicates and data evaluated statistically by using one way ANOVA (SPSS ver. 8.0) and means comparison were performed with a significant differences $(\mathrm{p}<0.05)$ (Steel et al., 1997).

\section{Results and discussion}

This study explored whether there would be aflatoxin production in rice grains from different drying and storage treatments in Pakistan. In single step mechanical drying, it takes 6 hours to reduce the moisture content from $22 \%$ to $11-12 \%$ and after storage at $30^{\circ} \mathrm{C}$ and under $60 \%$ moisture content for 210 days showed maximum aflatoxins accumulation in rice karnel was 4.35 ppb while six samples showed below detection level of aflatoxins accumulation (Table I). On the other have, some samples showed little aflatoxins accumulation. It was observed that when the moisture content of the dried paddy rice was in the range 
Table I. Aflatoxin accumulation in paddy rice samples during 210 days of storage using single step drying pattern

\begin{tabular}{|c|c|c|c|c|}
\hline $\begin{array}{l}\text { Sample } \\
\text { No. }\end{array}$ & Moisture \% & $\begin{array}{l}\text { Temperature } \\
{ }^{\circ} \mathrm{C} / \\
\text { Humidity } \%\end{array}$ & $\begin{array}{l}\text { Storage } \\
\text { time in } \\
\text { days }\end{array}$ & $\begin{array}{c}\text { Total Aflatoxin } \\
\text { (B1,B2,G1,G2) } \\
\text { (ppb) }\end{array}$ \\
\hline 1 & 11.4 & $32 / 60$ & 210 & 1.9 \\
\hline 2 & 11.5 & $32 / 60$ & 210 & 1.4 \\
\hline 3 & 12.2 & $32 / 60$ & 210 & 0.64 \\
\hline 4 & 12 & $32 / 60$ & 210 & 1.8 \\
\hline 5 & 11.8 & $32 / 60$ & 210 & 0.61 \\
\hline 6 & 11.5 & $32 / 60$ & 210 & ND \\
\hline 7 & 12.0 & $32 / 60$ & 210 & ND \\
\hline 8 & 12.2 & $32 / 60$ & 210 & ND \\
\hline 9 & 11.8 & $32 / 60$ & 210 & 2.9 \\
\hline 10 & 11.5 & $32 / 60$ & 210 & 4.35 \\
\hline 11 & 11.0 & $32 / 60$ & 210 & 1.2 \\
\hline 12 & 11.5 & $32 / 60$ & 210 & 0.90 \\
\hline 13 & 11.0 & $32 / 60$ & 210 & ND \\
\hline 14 & 11.5 & $32 / 60$ & 210 & ND \\
\hline 15 & 12.4 & $32 / 60$ & 210 & 1.1 \\
\hline 16 & 12.0 & $32 / 60$ & 210 & 2.8 \\
\hline 17 & 12.1 & $32 / 60$ & 210 & 0.52 \\
\hline 18 & 11.5 & $32 / 60$ & 210 & 0.53 \\
\hline 19 & 11.2 & $32 / 60$ & 210 & 2.4 \\
\hline 20 & 11.6 & $32 / 60$ & 210 & 1.3 \\
\hline 21 & 12.1 & $32 / 60$ & 210 & ND \\
\hline 22 & 12.0 & $32 / 60$ & 210 & 0.73 \\
\hline 23 & 11.8 & $32 / 60$ & 210 & 1.0 \\
\hline 24 & 11.6 & $32 / 60$ & 210 & 1.7 \\
\hline 25 & 11.5 & $32 / 60$ & 210 & 3.0 \\
\hline
\end{tabular}

$\mathrm{ND}=$ Not Detected, Detection limit $=0.5 \mathrm{ppb}$

between 11.0-12.0\%, six samples did not show any accumulation of aflatoxins. However, when moisture content was little above $12 \%$ then aflatoxins accumulation was observed almost all the samples. However this accumulation is below the recommended level. This finding suggested that drying below $12 \%$ moisture content provide better protection of consumers from aflatoxicosis. On the other hand in two step traditional drying methods, the moisture content of paddy rice was above $12 \%$ therefore aflatoxin accumulation was occurred in all the samples and maximum aflatoxins content was recorded as $27 \mathrm{ppb}$ in two step drying method (Table II). This study results showed that the single step drying method was safe as there was no development of aflatoxins during 210 days of storage as compared to two step drying methods, because in single step drying, paddy rice are dried up to safe moisture contents which does not favour the fungal growth. Similar results were reported by George (1988) who illustrated that fungi require moisture to cause food spoilage by producing secondary metabolites within moisture limits of $13-13.2 \%$. When the high moistured semi dried rice is filled in bags, heat is produced due to respiration. Hot and humid environment of paddy rice in filled bags provide favorable environment for the growth of aflatoxins. In another report, Carlos et al. (2000) reported that hot and 
Table II. Aflatoxin accumulation in paddy rice samples during 210 days of storage using two step drying pattern

\begin{tabular}{|c|c|c|c|c|c|}
\hline \multirow{2}{*}{$\begin{array}{c}\text { Sample } \\
\text { No. } \\
1\end{array}$} & \multicolumn{2}{|c|}{$\frac{\text { Moisture } \%}{\text { Semidried Final dried }}$} & \multirow{2}{*}{$\begin{array}{l}\text { Temperature }{ }^{\circ} \mathrm{C} / \\
\text { Humidity } \%\end{array}$} & \multirow{2}{*}{$\begin{array}{l}\text { Storage time } \\
\text { in days }\end{array}$} & \multirow{2}{*}{$\begin{array}{c}\text { Total Aflatoxin } \\
\begin{array}{c}(\mathrm{B} 1, \mathrm{~B} 2, \mathrm{G} 1, \mathrm{G} 2) \\
(\mathrm{ppb})\end{array} \\
16\end{array}$} \\
\hline & 18 & 13 & & & \\
\hline 2 & 18 & 13 & $32 / 60$ & 210 & 3.8 \\
\hline 3 & 18 & 14 & $32 / 60$ & 210 & 3.9 \\
\hline 4 & 18 & 13.5 & $32 / 60$ & 210 & 18 \\
\hline 5 & 18.5 & 14 & $32 / 60$ & 210 & 4.3 \\
\hline 6 & 18.5 & 13.5 & $32 / 60$ & 210 & 17.5 \\
\hline 7 & 18 & 14 & $32 / 60$ & 210 & 15 \\
\hline 8 & 19 & 13.7 & $32 / 60$ & 210 & 27 \\
\hline 9 & 18 & 13 & $32 / 60$ & 210 & 2.4 \\
\hline 10 & 17 & 13 & $32 / 60$ & 210 & 13 \\
\hline 11 & 17 & 12.0 & $32 / 60$ & 210 & 6 \\
\hline 12 & 18 & 12.5 & $32 / 60$ & 210 & 12 \\
\hline 13 & 17 & 14.0 & $32 / 60$ & 210 & 6.2 \\
\hline 14 & 18 & 13.0 & $32 / 60$ & 210 & 6.2 \\
\hline 15 & 17.6 & 12.4 & $32 / 60$ & 210 & 4.3 \\
\hline 16 & 18 & 13.0 & $32 / 60$ & 210 & 3.1 \\
\hline 17 & 17.8 & 12.5 & $32 / 60$ & 210 & 5.0 \\
\hline 18 & 18.2 & 13.0 & $32 / 60$ & 210 & 5.5 \\
\hline 19 & 18.0 & 13.5 & $32 / 60$ & 210 & 3.7 \\
\hline 20 & 18.0 & 14.0 & $32 / 60$ & 210 & 15.2 \\
\hline 21 & 18.0 & 13.5 & $32 / 60$ & 210 & 6.2 \\
\hline 22 & 17.7 & 13.0 & $32 / 60$ & 210 & 15 \\
\hline 23 & 18.2 & 13.0 & $32 / 60$ & 210 & 3.0 \\
\hline 24 & 17.5 & 12.6 & $32 / 60$ & 210 & 10 \\
\hline 25 & 18.0 & 13.0 & $32 / 60$ & 210 & 4.5 \\
\hline
\end{tabular}

humid environment during prolongs storage favours aflatoxin contamination. The results of this study will contribute in formulation of local standards and legislative measures of permissible limit of aflatoxin in food grains in Pakistan. Single step drying technology should be introduced to the farmers and government initiative and financial assistance to install mechanical dryer in rice producing area could be done to produce safe rice for the people.

However, further studies relating to aflatoxins on rice storage could examine the effects of other common practices of farmers such as keeping wet grains over different periods, piling bundles of cut crop for different periods, seasonal variations, and low cost technology in drying could improve the safety of the crops for human consumption.

\section{Conclusion}

Aflatoxins are highly hazardous for livestock, poultry, and people and seriously impair human health and productivity. Drying method significantly affect the occurrence of aflatoxins in food commodities during storage. Cereal grains must be dried up to safe moisture level $<14 \%$ in single step drying after harvest and avoid short term or long term storage after semidrying the food commodities. 


\section{References}

Ashiq S (2015), Natural Occurrence of Mycotoxins in Food and Feed: Pakistan Perspective, Compr. Rev. Food Sci. Food Saf. 149(2): 159-175. DOI: .org/ 10. $1111 / 1541-4337.12122$

Accinelli C, Abbas HK, Vicari A and Shier WT (2014), Aflatoxin contamination of corn under different agro-environmental conditions and biocontrol applications, Crop Prot. 63: 9-14.

Bradford KJ, Dahal P, Asbrouck JV, Kunusoth K, Bello P, Thompson J and Wu F (2017), The dry chain: Reducing postharvest losses and improving food safety in humid climates, Trends in Food Sci. Tech. 71: 84-93. DOI: org/10.1016/j.tifs.2017.11.002

Bennett JW and Klich M (2003), Mycotoxins, Clin Microbiol Rev. 16(3): 497-516.

Creppy EE (2002), Update of survey, regulation and toxic effects of mycotoxins in Europe, Toxicol Lett. 127: 19-28.

Castano SM, Medina A and Magan N (2017), Comparison of dry matter losses and aflatoxin $\mathrm{B}_{1}$ contamination of paddy and brown rice stored naturally or after inoculation with Aspergillus flavus at different environmental conditions, J. Stored Prod. Res. 73: 47-53. DOI: org/10.1016/j.jspr.2017.06.004

Carlos AP, Reinaldo BO, Paulo D and Benedito C (2000), Mycoflora and aflatoxigenic species in derivatives of milled rice, Ci^enc. Tecnol. Aliment. 20(1): 37-49.

de Ruyck K, De Boevre M, Huybrechts I and De Saeger S (2015), Dietary mycotoxins, co-exposure, and carcinogenesis in humans: Short review, Mutat Res Rev Mutat Res. 766: 32-41. DOI: org/10.1016/j.mrrev.2015.07.003

Fung F and Clark RF (2004), Health effects of mycotoxins: A toxicological overview, J. Toxicol. Clin Toxicol. 42: 217-234. DIO: org/10.1081/CLT-120030947

Genkawa T, Uchino T, Inoue A, Tanaka F and Hamanaka D (2008), Development of a low-moisture-content storage system for brown rice: storability at decreased moisture contents, Biosyst. Eng. 99(4): 515-522. DOI: 10.1016/j.biosystemseng.2007.12.011
Georage NA (1988), Plant Pathology, 11 th Ed., Academic Press, New York, USA.

Khan MA (2010), Post Harvest Losses of Rice, Trade Development Authority of Pakistan, Karachi, Pakistan.

Khan AS and Salim M (2005), Rice harvesting and threshing, Pak J. Food Sci. 15(1-2): 45-52.

Kumar D and Kalita P (2017), Reducing Postharvest Losses during Storage of Grain Crops to Strengthen Food Security in Developing Countries, Foods 6(1): 8. DOI: $10.3390 /$ foods 6010008

Medina A, Akbar A, Baazeem A, Rodriguez A and Magan N (2017), Climate change, food security and mycotoxins: Do we know enough?, Fungal Biol. Rev. 31(3): 143-154. DOI: org/10.1016/j.fbr.2017.04.002

Mehan VK, Bhavanishankar TN and Bedi JS (1985), Comparison of Different Methods for Extraction and Estimation of Aflatoxin B1 in Groundnut, J. Food Sci. Tech. 22: 123-125.

Mannaa M, Oh JY and Kim KD (2017), Microbe-mediated control of Aspergillus flavus in stored rice grains with a focus on aflatoxin inhibition and biodegradation, Ann Appl Biol. 171(3): 376-392.

Mohapatra D, Kumar S, Kotwaliwale N and Singh KK (2017), Critical factors responsible for fungi growth in stored food grains and non-chemical approaches for their control, Ind. Crops Prod. 108: 162-182.

Medina A, Gilbert MK, Mack BM, Brian GRO, Rodriguez A, Bhatnagar D, Payne G and Magan N (2017), Interactions between water activity and temperature on the Aspergillus flavus transcriptome and aflatoxin B production, Int. J. Food Microbiol. 256: 36-44. DOI: org/10.1016/j.ijfoodmicro.2017.05.020

Nisa A, Zahra N and Butt YN (2016), Comparative study of aflatoxins in brown rice samples of local and import quality, Int. Food Res. J. 23(1): 243-247.

Neme K and Mohammed A (2017), Mycotoxin occurrence in grains and the role of postharvest management as a mitigation strategies. A review, Food Cont. 78: 412-425.

Nisa A, Zahra N, Butt YN and Hina S (2014), Aflatoxins; A Potential Threat to Human Health, Pak J. Food Sci. 24(4): 256-271. 
Nisa A, Zahra N and Hina S (2014), Detection of Aflatoxins in Rice Samples. Bangladesh J. Sci. Ind. Res. 49(3): 189-194. DOI: org/10.3329/bjsir.v49i3.22134

Nguyen CN and Kunze OR (1984), Fissures related to post-drying treatments in rough rice, Cereal Chem. 6(1): 63-68.

Prietto L, Moraes PS, Kraus RB, Meneghetti V, Fagundes CAA and Furlong EB (2015), Post-harvest operations and aflatoxin levels in rice (Oryza sativa), Crop Prot. 78: 172-177. DOI: org/10.1016/j.cropro.2015.09.011

Paterson RRM and Lima N (2010), How will climate change affect mycotoxins in food?, Food Res. Int. 43(7): 1902-1914.
Riaz M, Ismail T and Akhtar S (2017), Harvesting, Threshing, Processing, and Products of Rice In: Rice Production Worldwide, Springer, Cham, pp 419-453.

Siebenmorgen TJ and Meullenet J (2004), Impact of drying, storage, and milling on rice quality and functionality In: Rice chemistry and technology, American Association of Cereal Chemists, St. Paul, pp 301-328.

Steel RGD, Torrie JH and Dicky DA (1997), Principles and Procedures of Statistics. A Biometrical Approach, $3^{\text {rd }}$ Ed., McGraw Hill Book Co. Inc., New York.

Taechapairoj C, Prachayawarakorn S and Soponronnarit S (2007), Characteristics of rice dried in Superheated-steam fluidized bed, Drying Technol. Int. J. 22(4): 719-743. 